Research Article

\title{
Genotypic and Phenotypic Characterizations of Methicillin-Resistant Staphylococcus aureus (MRSA) on Frequently Touched Sites from Public Hospitals in South Africa
}

\author{
Siyethaba Mkhize, ${ }^{1,2}$ Daniel G. Amoako $\mathbb{D}^{3},{ }^{3}$ Christiana O. Shobo, ${ }^{1}$ Oliver T. Zishiri $\mathbb{D}^{2}{ }^{2}$ \\ and Linda A. Bester $\mathbb{D}^{1}$ \\ ${ }^{1}$ Biomedical Resource Unit, School of Laboratory Medicine and Medical Sciences, College of Health Sciences, \\ University of KwaZulu-Natal, Durban 4000, South Africa \\ ${ }^{2}$ Discipline of Genetics, School of Life Sciences, College of Agriculture Engineering and Science, University of KwaZulu-Natal, \\ Durban 4000, South Africa \\ ${ }^{3}$ Antimicrobial Research Unit, College of Health Sciences, University of KwaZulu-Natal, Durban 4000, South Africa \\ Correspondence should be addressed to Linda A. Bester; besterl@ukzn.ac.za
}

Received 24 July 2021; Accepted 1 October 2021; Published 23 October 2021

Academic Editor: Joseph Falkinham

Copyright (C) 2021 Siyethaba Mkhize et al. This is an open access article distributed under the Creative Commons Attribution License, which permits unrestricted use, distribution, and reproduction in any medium, provided the original work is properly cited.

\begin{abstract}
The hospital environment acts as a reservoir in the transmission of pathogens, such as MRSA, which may cause hospital-acquired infections. This study aimed to ascertain the prevalence, genetic relatedness, antibiotic resistance, and virulence profile of MRSA on some frequently touched hospital sites in South Africa. A total of 777 swabs were randomly collected from 11 frequently touched sites in the hospital environment of three wards of four public hospitals in the KwaZulu-Natal province of South Africa. Isolation of S. aureus and confirmation were done using genotypic and phenotypic methods. Antibiotic susceptibility testing was performed using the Kirby-Bauer disk-diffusion method. MRSA isolates were determined by the presence of the mecA gene. Virulence and resistance genes were detected using a standard monoplex PCR assay. ERIC-PCR was conducted to evaluate the genetic relatedness. An overall prevalence of $12.7 \%$ for S. aureus isolates was obtained. Out of these, $89.9 \%$ (89/99) were confirmed to be MRSA. The sites with the highest prevalence were the occupied beds $(16.2 \%(16 / 99))$, unoccupied beds $(16.2 \%(16 / 99))$, patient files $(14.1 \%(14 / 99))$, ward phones $(13.1 \%(13 / 99))$, and nurses' tables $(14.1 \%(14 / 99))$. The virulence genes with the highest observed frequency were hld (87 $(87.9 \%))$ and $L u k S / F-P V(53$ (53.5\%)). The resistance genes with the highest frequency were the tet $M$ and tetK genes detected in $60(60.6 \%)$ and 57 (57.6\%) isolates, respectively. The ERIC-PCR results obtained indicated a high level of genetic diversity; however, intraclonal (within a hospital) and interclonal (between hospitals) clusters of MRSA were observed. The study showed that MRSA can contaminate various surfaces, and this persistence allows for the dissemination of bacteria within the hospital environment. This highlights the need for improved infection prevention and control (IPC) strategies in public hospitals in the country to curb their potential transmission risks.
\end{abstract}

\section{Introduction}

A hospital-acquired infection (HAI) or nosocomial infection develops during hospitalisation or within 48 hours after the patient has been discharged. In most cases, this is not the initial cause of hospital admission [1]. Staphylococcus aureus (S. aureus) is considered one of the most important [2] pathogens responsible for HAIs. HAIs are a financial burden in developed and developing countries causing significant strain on the economy due to the high cost of treatments and increased mortality and morbidity rates that are associated with these types of infections [3-5]. In addition, $S$. aureus is one of eight significant pathogens listed by the Global Antimicrobial Resistance Surveillance System (GLASS) alongside Shigella spp., Salmonella spp., Streptococcus pneumoniae, Klebsiella pneumoniae, Neisseria gonorrhoeae, Acinetobacter spp., and Escherichia coli [6]. 
S. aureus is a versatile pathogen that causes a variety of diseases, from respiratory to skin infections [7], as it colonises the skin and mucosal membranes of animals and humans [8]. Lung infections are predominantly of nosocomial origin. In contrast, skin infections are primarily of a community-acquired nature [7]. The severity of the disease ranges from minor skin infections to life-threatening conditions (soft tissue abscesses, toxic shock syndrome, pneumonia, septicaemia, bacteraemia, and endocarditis) [9]. $S$. aureus strains have become resistant to a diverse range of antibiotics resulting in multidrug-resistant (MDR) strains. There is an increasing shortage of antibiotics that can be used to treat these infections [10]. Methicillin is one of the antibiotics used to treat $S$. aureus infections; the term MRSA is used for methicillin-resistant $S$. aureus strains. MRSA is a global multidrug-resistant human pathogen present in hospital and community environments [11].

Environmental sampling of the hospital surfaces indicated that ESKAPE (Enterococcus faecium, Staphylococcus aureus, Klebsiella pneumoniae, Acinetobacter baumannii, Pseudomonas aeruginosa, and Enterobacter spp.) pathogens are shed into the hospital environment by patients and survive on surfaces for an extended period as they are difficult to destroy through cleaning and disinfection [12]. Within the hospital, MRSA has been isolated from hospital equipment in Ireland [13], hospital linen in France [14], telephones in Nigeria [15], and air [16]. However, there is a dearth of information on the prevalence and characterization of MRSA within the hospital environments in South Africa. Therefore, there is a need to determine if current infection, prevention, and control (IPC) strategies are adequate to curtail MRSA in the hospital environment of public hospitals. Given this information, the aims of this study were two-fold: firstly, to examine the prevalence of S. aureus and MRSA on inanimate surfaces in South African public hospitals; secondly, to determine the genetic diversity, antibiotic resistance, and virulence profiles of the collected isolates.

\section{Materials and Methods}

2.1. Sample Site. Swab samples were collected over three months from September to November 2017. Four provincial public hospitals are classified under the South African National Health Act of 2003 [17] according to their different levels of healthcare viz. central (hospital A), tertiary (hospital B), regional (hospital C), and district (hospital D). Central/ specialized hospitals, with bed sizes between 800 and 1200, accept referrals from both district and regional hospitals. Tertiary hospitals have 400 to 800 beds available and provide specialised services such as those offered by a regional hospital. They also receive referrals from regional hospitals; however, referrals are not limited to provincial boundaries. Regional hospitals which have between 200 and 800 beds receive referrals from several district hospitals and provide services to a specific regional population. District hospitals have between 50 and 600 beds, depending on their classification of either being small, medium, or large. These hospitals receive outreach and support from specialists based at regional hospitals. Samples were collected from three wards viz. intensive care unit (ICU) and paediatric and general wards of the studied hospitals.

2.2. Sample Collection. A total of 777 swabs were collected from eleven predetermined and frequently touched surfaces in the hospital environment viz. ward phones, nurses' tables, drip stands, sinks, blood pressure (bp) machines, patient files, occupied and unoccupied beds, ventilators, mops, and the utility room door handles (Supplementary Table S1). The stratified random sampling method was used. Samples were collected by gently swabbing approximately a $5 \mathrm{~cm}$ circumference of the surfaces using capped Amies Agar swabs in translucent transport media (Thermo Fisher Scientific, Waltham, MA, USA). The swabs were then placed in a cooler box with ice for transportation to the laboratory and processed within four hours upon arrival.

\subsection{Phenotypic Identification and Isolation of Staphylococcus} aureus. For enrichment purposes, swabs were broken off into labelled $50 \mathrm{~mL}$ blue-capped centrifuge tubes containing $20 \mathrm{~mL}$ of tryptic soy broth (TSB) (Sigma-Aldrich, Germany) and incubated at $37^{\circ} \mathrm{C}$ for $\pm 24 \mathrm{hrs}$ while stirred (Steyn Scientific, USA). After incubation, a loopful of broth was aseptically inoculated and streaked onto plates containing chromogenic agar, HiChrome $\mathrm{T}^{\mathrm{TM}}$ Aureus Agar Base (HiMedia, India), and supplemented with $2 \%$ egg-yolk tellurite emulsion (HiMedia, India). The plates were incubated (Shel Lab, Sheldon Manufacturing Inc., USA) at $37^{\circ} \mathrm{C}$ for \pm 24 hrs. The presumptive $S$. aureus colonies were subsequently stored in cryovials containing TSB supplemented with 10\% glycerol (VWR International Life Sciences, Amresco, Parkway) until further analyses.

2.4. Deoxyribonucleic Acid (DNA) Extraction. Total genomic DNA was extracted using the conventional boiling method [18]. Briefly, colonies from pure S. aureus cultures were suspended in $300 \mu \mathrm{L}$ of TE (Tris-EDTA) $(10 \mathrm{mM}$ Tris- $\mathrm{HCl}$ $\mathrm{pH} 8.0$ with $1 \mathrm{mM}$ EDTA) buffer and vortexed to homogenise the cells. The suspension was boiled in a heating block at $100^{\circ} \mathrm{C}$ for 10 minutes with immediate cooling on ice for 5 minutes. The tubes were centrifuged (Beckman Coulter Microfuge 16, United States) at $14000 \times g$ for 5 minutes. The supernatant was transferred into a new sterile tube and stored at $-20^{\circ} \mathrm{C}$ for PCR use. Nanodrop readings were taken to measure the concentration and purity of isolated DNA using the Thermo Scientific Nanodrop 2000, UV-Vis spectrophotometer (Wilmington, Delaware, USA). Readings within $1.8-1.9$ at the ratio of 260/280 were regarded as pure DNA. Nuclease-free water (Thermo Fisher Scientific, Waltham, MA USA) was used to adjust the DNA concentration accordingly for PCR.

2.5. Molecular Confirmation of $S$. aureus. Primers for the polymerase chain reaction (PCR) were synthesised at Inqaba Biotechnology (South Africa). The primer sequences, annealing temperatures, and product sizes are 
indicated in Table 1. The species-specific thermonuclease $n u c$ gene [19] was used for the identification of S. aureus. The positive control S. aureus ATCC 25913 and negative control (nuclease-free water) were used for all reactions. The Bio-Rad T100 ${ }^{\mathrm{TM}}$ Thermal Cycler (Singapore) was used to carry out the PCR assays. A $15 \mu \mathrm{L}$ reaction contained $7 \mu \mathrm{L}$ of DreamTaq Green PCR Master Mix (2X) (Thermo Fisher Scientific, Waltham, MA, USA), $0.5 \mu \mathrm{L}$ of both reverse and forward primers of a $20 \mu \mathrm{M}$ primer concentration, $3 \mu \mathrm{L}$ of template DNA, and $4 \mu \mathrm{L}$ of nuclease-free water making a total reaction volume of $15 \mu \mathrm{L}$. Gel electrophoresis was carried out by loading the PCR products into a $1.5 \%$ (w/vol) agarose gel with $5 \mu \mathrm{L}$ of $10 \mathrm{mg} / \mathrm{ml}$ ethidium bromide (Thermo Fisher Scientific, Waltham, MA, USA) and run at 100 volts for 30 minutes in a tank containing Tris-borate-EDTA (pH 8.3, 1X). A 100 bp DNA ladder (New England Biolabs, Ipswich, USA) was used as the molecular weight marker. Gels were viewed on the ChemiDoc ${ }^{\mathrm{TM}}$ Imaging System (Bio-Rad Laboratories Inc., USA).

2.6. Antimicrobial Susceptibility Testing of Isolated Bacteria. Antimicrobial susceptibility testing was performed using the Kirby-Bauer disk-diffusion method, according to the Clinical and Laboratory Standards Institute M100-S27 guidelines [23], using Mueller-Hinton agar (Oxoid, England). An inoculum was suspended in sterile water and developed using the 0.5 McFarland standard (DEN-1B McFarland, Biosan, Latvia). All antibiotics were sourced from Oxoid, England. The following antibiotics were used: erythromycin (macrolides) (15 $\mu \mathrm{g})$, cefoxitin (penicillins) $(30 \mu \mathrm{g})$, penicillin (penicillins) (10 units), tetracycline (tetracyclines) $(30 \mu \mathrm{g})$, linezolid (lipopeptides) $(30 \mathrm{ug})$, clindamycin (lincosamides) $(2 \mu \mathrm{g})$, quinupristin-dalfopristin (streptogramins) $(15 \mu \mathrm{g})$, ciprofloxacin (fluoroquinolones) $(5 \mu \mathrm{g})$, and rifampicin (ansamycins) $(5 \mu \mathrm{g})$. These antibiotics were selected based on a review conducted by Gold and Pillai (2009) for their clinical use in human therapy. S. aureus ATCC 25923 was used as the control strain. Isolates were considered multidrug resistant (MDR) when they showed resistance to at least one antibiotic in three or more different antibiotic classes [24].

2.7. Genotypic Identification of Resistance and Virulence Genes. DNA extraction and volumes used to conduct singleplex reactions for the resistance and virulence genes were as described previously (Table 1). The PCR primers and conditions followed are indicated in Table 1 . The resistance genes, aac (6')-aph (2"), blaZ, tet $K$, tet $M$, and erm $C$, which confer resistance to aminoglycoside, macrolide-lincosamide-streptogramin $\mathrm{B}\left(\mathrm{MLS}_{\mathrm{B}}\right)$, tetracycline, and erythromycin, respectively, were identified. Virulence genes for Panton-Valentine leucocidin (LukS/F-PV) and alpha and delta haemolysin ( $h l a$ and $h l d$ ) were also identified. The positive control S. aureus ATCC 25913 and negative control (nuclease-free water) were used for all the reactions conducted.
2.8. Analysis of the Genetic Diversity of S. aureus Using Enterobacterial Repetitive Intergenic Consensus (ERIC) PCR. Genomic DNA was extracted using the Quick-DNA ${ }^{\mathrm{TM}}$ Miniprep Plus kit (Zymo Research, USA) according to the manufacturer's instructions. The purity and concentration were measured using the Thermo Scientific Nanodrop 2000, UV-Vis spectrophotometer (Wilmington, Delaware, USA). A reaction volume of $25 \mu \mathrm{L}$ was set up: $12.5 \mu \mathrm{L}$ of DreamTaq Green PCR Master Mix 2X (Thermo Fisher Scientific, Waltham, MA, USA), $9.3 \mu \mathrm{L}$ of nuclease-free water, $3 \mu \mathrm{L}$ of template DNA, and $0.1 \mu \mathrm{L}$ of $100 \mathrm{mM}$ ERIC 1 ( $5^{\prime}$-CACTTAGGGGTCCTCGAATGTA-3') and ERIC 2 (5'-AAGTAAGTGATGGGGTGAGCG-3') primers (Inqaba Biotechnology, South Africa). The PCR conditions were as follows: $95^{\circ} \mathrm{C}$ for 2 minutes, 35 cycles of $30 \mathrm{~s}$ of denaturation at $90^{\circ} \mathrm{C}, 1 \mathrm{~min}$ of annealing at $52^{\circ} \mathrm{C}, 8 \mathrm{~min}$ of extension at $65^{\circ} \mathrm{C}$, and final elongation at $65^{\circ} \mathrm{C}$ for $16 \mathrm{~min}$. Gel electrophoresis was performed at $70 \mathrm{~V}$ for $75 \mathrm{~min}$. The ERIC-PCR gels were captured (ChemiDoc ${ }^{\mathrm{TM}}$ Imaging System (Bio-Rad Laboratories Inc., USA) and analysed using BioNumerics software version 6.6 Applied Maths NV (bioMérieux, SintMartens-Latem, Belgium). A dendrogram was produced using an unweighted pair group with arithmetic mean (UPGMA) method and Dice coefficient parameters of $1 \%$ tolerance and $0.5 \%$ optimisation.

2.9. Statistical Analysis. SPSS software version 25 (IBM SPSS Statistics) was used for statistical analyses using a probability value of less than $0.05(p<0.05)$ for significance. Fisher's exact and Pearson's chi-square tests were used to determine the significance of the relationship between the genes detected and the hospital/site/wards from which the samples originated. For each statistical model, the dependent variable was the virulence gene presence $(0=$ absent; $1=$ present $)$.

\section{Results}

3.1. Prevalence of Staphylococcus aureus. From the 777 samples collected, a total of $99(12.7 \%)$ S. aureus isolates were obtained over a period of three months. The prevalence of S. aureus isolates per hospital was as follows: the central hospital (hospital A) had a majority of $23.2 \%$ (23/99), the tertiary hospital (hospital B) had a prevalence of $23.2 \%$ (23/ 99), the regional hospital (hospital C) had a prevalence of $33.3 \%$ (33/99), and the district hospital (hospital D) had a prevalence of $20.2 \%$ (20/99). With regard to the wards, the general ward revealed the highest prevalence with $41.4 \%$ (41/ 99) isolates, followed by the paediatric ward (34.3\% (34/99)) and ICU (24.2\% (24/99)); no statistical significance was observed $(p \geq 0.05)$. Isolates were recovered from all the eleven sites sampled. The sites with the highest prevalence (indicated in Figure 1) were the occupied beds (16.2\% (16/ 99)), unoccupied beds $(16.2 \%(16 / 99))$, patient files $(14.1 \%$ $(14 / 99))$, ward phones $(13.1 \%(13 / 99))$, and nurses' tables $(14.1 \%(14 / 99))$. The sites with the lowest prevalence were the blood pressure apparatus $(6.1 \%$ (6/99)), drip stands (6.1\% (6/ $99)$ ), ventilators $(6.1 \%(6 / 99))$, door handles (4\% (4/99)), mops $(3.0 \%(3 / 99))$, and sink $(1.0 \%(1 / 99))$. The mecA gene 
TABLE 1: Cycling conditions and primer sequences for genes presented in this study.

\begin{tabular}{|c|c|c|c|c|c|c|}
\hline & Description & Gene & Primer sequence & PCR conditions & $\begin{array}{c}\text { bp } \\
\text { size }\end{array}$ & References \\
\hline $\begin{array}{l}\text { Species- } \\
\text { specific gene }\end{array}$ & Thermonuclease & nuc & $\begin{array}{c}\text { F-GCGATTGATGGTGATACGGTT } \\
\text { R-AGCCAAGCCTTGACGAACTAAAGC }\end{array}$ & $\begin{array}{l}30 \mathrm{~s} 95^{\circ} \mathrm{C}, 30 \mathrm{~s} \\
55^{\circ} \mathrm{C}, 1 \mathrm{~min} \\
72^{\circ} \mathrm{C}\end{array}$ & 270 & [19] \\
\hline \multirow{3}{*}{$\begin{array}{l}\text { Virulence } \\
\text { genes }\end{array}$} & \multirow{2}{*}{ Haemolysin } & hla & $\begin{array}{c}\text { F-CTGATTACTATCCAAGAAATTCGATTG } \\
\text { R-CTTTCCAGCCTACTTTTTTATCAGT }\end{array}$ & $\begin{array}{l}30 \mathrm{~s} 94^{\circ} \mathrm{C}, 30 \mathrm{~s} \\
55^{\circ} \mathrm{C}, 1 \mathrm{~min} \\
72^{\circ} \mathrm{C}\end{array}$ & 209 & {$[20]$} \\
\hline & & hld & $\begin{array}{c}\text { F- } \\
\text { AAGAATTTTTATCTTAATTAAGGAAGGAGTG } \\
\text { R-TTAGTGAATTTGTTCACTGTGTCGA }\end{array}$ & $\begin{array}{l}30 \mathrm{~s} 94^{\circ} \mathrm{C}, 30 \mathrm{~s} \\
55^{\circ} \mathrm{C}, 1 \mathrm{~min} \\
72^{\circ} \mathrm{C}\end{array}$ & 111 & {$[20]$} \\
\hline & $\begin{array}{l}\text { Panton-Valentine } \\
\text { leukocidin }\end{array}$ & $\begin{array}{l}L u k S / F- \\
\quad P V\end{array}$ & $\begin{array}{c}\mathrm{F}- \\
\text { ATCATTAGGTAAAATGTCTGGACATGATCCA } \\
\text { R-GCATCAAGTGTATTGGATAGCAAAAGC }\end{array}$ & $\begin{array}{l}30 \mathrm{~s} 95^{\circ} \mathrm{C}, 45 \mathrm{~s} \\
60^{\circ} \mathrm{C}, 1 \mathrm{~min} \\
72^{\circ} \mathrm{C}\end{array}$ & 443 & {$[20]$} \\
\hline \multirow{6}{*}{$\begin{array}{l}\text { Resistance } \\
\text { genes }\end{array}$} & Erythromycin & ermC & $\begin{array}{l}\text { F-CTTGTTGATCACGATAATTTCC } \\
\text { R-ATCTTTTAGCAAACCCGTATTC }\end{array}$ & $\begin{array}{l}30 \mathrm{~s} 94^{\circ} \mathrm{C}, 30 \mathrm{~s} \\
55^{\circ} \mathrm{C}, 1 \mathrm{~min} \\
72^{\circ} \mathrm{C}\end{array}$ & 190 & {$[21]$} \\
\hline & \multirow{2}{*}{ Tetracycline } & tetK & $\begin{array}{l}\text { F-TCGATAGGAACAGCAGTA } \\
\text { R-CAGCAGATCCTACTCCTT }\end{array}$ & $\begin{array}{c}30 \mathrm{~s} 94^{\circ} \mathrm{C}, 30 \mathrm{~s} \\
55^{\circ} \mathrm{C}, 1 \mathrm{~min} \\
72^{\circ} \mathrm{C}\end{array}$ & 169 & {$[21]$} \\
\hline & & tetM & $\begin{array}{l}\text { F-GTGGACAAAGGTACAACGAG } \\
\text { R-CGGTAAAGTTCGTCACACAC }\end{array}$ & $\begin{array}{c}50 \mathrm{~s} 95^{\circ} \mathrm{C}, 1 \mathrm{~min} \\
55^{\circ} \mathrm{C}, 1 \mathrm{~min} \\
72^{\circ} \mathrm{C}\end{array}$ & 657 & {$[22]$} \\
\hline & Aminoglycosides & $\begin{array}{l}\operatorname{aac}\left(6^{\prime}\right)- \\
\operatorname{aph}\left(2^{\prime \prime}\right)\end{array}$ & $\begin{array}{l}\text { F-TAATCCAAGAGCAATAAGGGC } \\
\text { R-GCCACACTATCATAACCACTA }\end{array}$ & $\begin{array}{l}30 \mathrm{~s} 94^{\circ} \mathrm{C}, 30 \mathrm{~s} \\
55^{\circ} \mathrm{C}, 1 \mathrm{~min} \\
72^{\circ} \mathrm{C}\end{array}$ & 227 & {$[21]$} \\
\hline & Methicillin & $m e c A$ & $\begin{array}{l}\text { F-AACAGGTGAATTATTAGCACTTGTAAG } \\
\text { R-ATTGCTGTTAATATTTTTTGAGTTGAA }\end{array}$ & $\begin{array}{l}30 \mathrm{~s} 94^{\circ} \mathrm{C}, 30 \mathrm{~s} \\
55^{\circ} \mathrm{C}, 1 \mathrm{~min} \\
72^{\circ} \mathrm{C}\end{array}$ & 174 & {$[21]$} \\
\hline & $\beta$-Lactamase & blaZ & $\begin{array}{l}\text { F-ACTTCAACACCTGCTGCTTT } \\
\text { R-TGACCACTTTTATCAGCAAC }\end{array}$ & $\begin{array}{l}30 \mathrm{~s} 94^{\circ} \mathrm{C}, 30 \mathrm{~s} \\
55^{\circ} \mathrm{C}, 1 \mathrm{~min} \\
72^{\circ} \mathrm{C}\end{array}$ & 173 & {$[21]$} \\
\hline
\end{tabular}

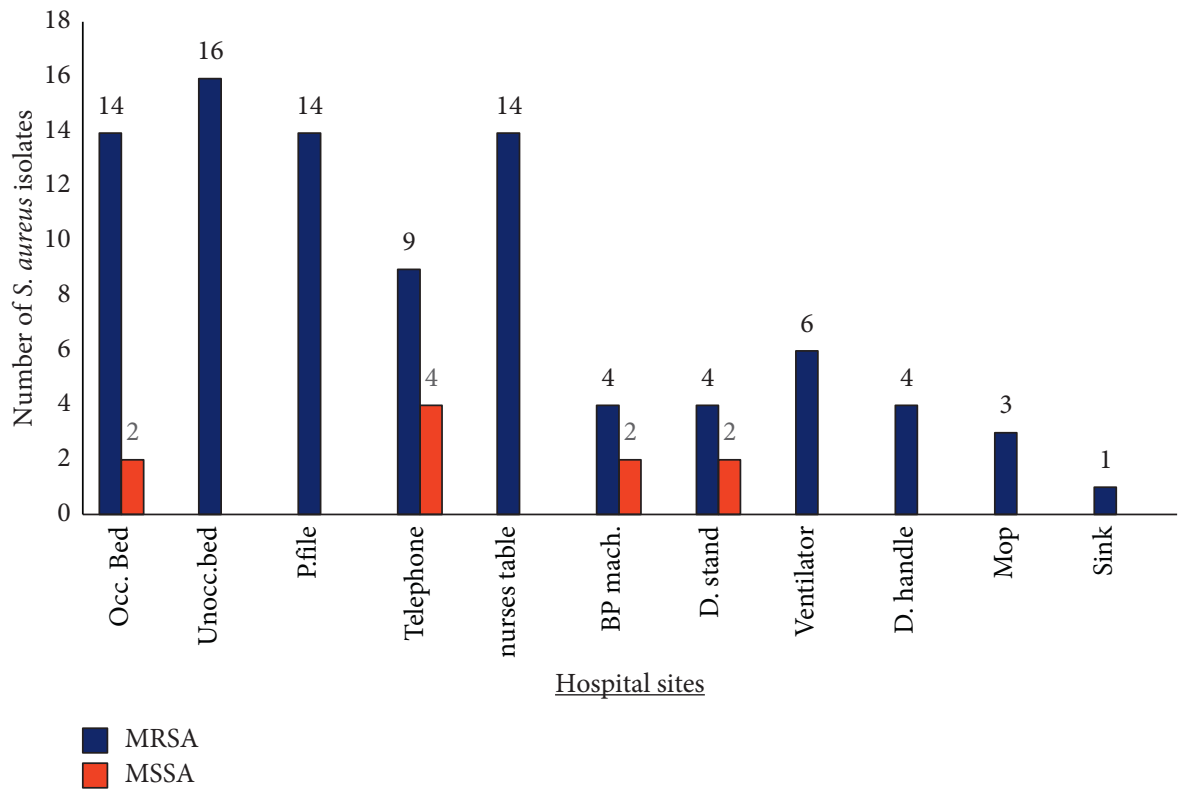

Figure 1: Prevalence of $S$. aureus (MRSA and MSSA) isolates sampled on eleven hospital sites within the wards and public hospitals investigated. 
was identified in $89.9 \%(89 / 99)$ of the S. aureus isolates. Only ten isolates were identified as methicillin-susceptible $S$. aureus (MSSA) (Figure 1). There was no statistical significance $(p>0.05)$ observed between the presence of the $m e c A$ gene and the hospital levels (Table S2).

3.2. Antibiotic Susceptibility Tests. Antimicrobial susceptibility testing was performed on all the 99 isolates collected. The isolates showed the highest resistance to penicillin $(60$, $60 \%)$, followed by cefoxitin (46, 46\%) and erythromycin (42, $42 \%)$. Less resistance was observed for quinupristin-dalfopristin $(29,29 \%)$, clindamycin $(27,27 \%)$, ciprofloxacin (18, $18 \%)$, tetracycline $(10,10 \%)$, rifampicin $(13,13 \%)$, and linezolid (3, 3\%). A total of 24/99 (24\%) of the isolates were multidrug resistant (MDR). Three isolates were resistant to six of the antibiotic classes: central hospital (A) (ward phone in paediatric wards), regional hospital (C) (ward phone in the ICU), and district hospital (D) (ventilator in the ICU).

3.3. Virulence and Resistance Genes. The virulence genes with the highest observed frequency were hld, haemolysin gene (87 (87.9\%)), and LukS/F-PV (53 (53.5\%)) encoding for the Panton-Valentine leucocidin gene. The hla (haemolysin) gene had the lowest frequency of 29 (29.3\%). The resistance genes with the highest frequency were the tet $M$ and tet $K$ genes encoding tetracycline resistance which were detected in $60(60.6 \%)$ and $57(57.6 \%)$ of the isolates, respectively. The blaZ and erm $C$ genes, encoding $\beta$-lactamase and erythromycin resistance, were present in $53(53.5 \%)$ of the isolates. The aac $\left(6^{\prime}\right)$-aph $\left(2^{\prime \prime}\right)$ gene had the lowest frequency of 29 (29.3\%).

Pearson's correlation analyses (Table S3) demonstrated that the mecA gene had a significant $(p<0.05)$ positive correlation with the tetK $(25.5 \%)$, ermC $(36.0 \%)$, blaZ (22.5\%), aac (6')-aph (2") (21.6\%), tetM (41.6\%), and LukS/ $F-P V(22.5 \%)$ genes. The study also identified that the aac $\left(6^{\prime}\right)$-aph $\left(2^{\prime \prime}\right)$ gene had a positive correlation $(p<0.05)$ to tetM (24.6\%), tetK (28.3\%), ermC (33.3\%), blaZ (37.7\%), and LukS/F-PV (19.9\%) genes. The blaZ gene had a significant positive correlation $(p<0.05)$ with ermC $(47.2 \%)$ and tetM $(20.2 \%)$. The tet $K$ gene had a strong and positive correlation $(p<0.05)$ with ermC (30.7\%), hla (24.3\%), tetM (35.4\%), and LukS/F-PV (34.8\%). ermC had a strong and positive correlation $(p<0.05)$ with tet $M(36.8 \%)$ and LukS/F-PV $(39.1 \%)$ (Table S3).

The relationships between the genes and site, genes and ward, and genes and hospital were examined. Pearson's chisquare and Fischer's exact test indicated that there was a significant relationship $(p<0.05)$ between the mecA gene and the site. A significant relationship $(p<0.05)$ was identified between the hospital and the tetK, erm $C, a a c\left(6^{\prime}\right)$ aph $\left(2^{\prime \prime}\right)$, and LukS/F-PV genes (Table S2).

3.4. Enterobacterial Repetitive Intergenic Consensus SequencePCR (ERIC-PCR) of MRSA. The enterobacterial repetitive intergenic consensus (ERIC-PCR) was used to determine the genetic diversity of MRSA isolates. Bands were produced for
87 of the isolates recovered; 2 of the isolates were nontypeable (these isolates showed no bands under ERIC-PCR conditions). The 87 isolates were assigned to 54 different ERIC types, namely, A-BC, based on a similarity index of $\geq 60 \%$ (shown by the solid red line) (Figure 2). The results obtained indicated a high level of genetic diversity in the study isolates. However, it was observed that $21 \%(18 / 87)$ of the $S$. aureus isolates were grouped into six major ERIC types: $\mathrm{F}(n=3), \mathrm{G}(n=3), \mathrm{P}(n=3), \mathrm{W} n=3), \mathrm{AC}(n=3)$, and AG $(n=3)$ (Figure 2). Of these six main ERIC types, three major ERIC types (P, W, and AC) were shared between different two hospitals, viz. district hospital (D) and regional hospital (C), indicating a potential interclonal spread of MRSA. More so, the AG $(n=3)$ cluster indicated that isolates from the ward telephone $(n=2)$ and unoccupied bed $(n=1)$ within the paediatrics ward of the tertiary hospital (B) belonged to the same ERIC type, also suggesting a possible intraclonal spread of MRSA.

\section{Discussion}

The sanitation of a hospital environment plays a crucial role in spreading pathogenic organisms such as MRSA [25]. MRSA can be transferred from person to person or from person to frequently touched objects in the hospital environment, and vice versa [15]. The overall prevalence of S. aureus obtained was $12.7 \%$ (99/777) which comprised 89 isolates of MRSA (methicillin-resistant $S$. aureus) and ten isolates of MSSA (methicillin-susceptible S. aureus). The result obtained indicated a low prevalence of MSSA. Although the reported MSSA prevalence was low, MRSA and MSSA do not differ in the diseases they cause [26]. In Africa, a lower prevalence rate of $2.7 \%(1 / 37)$ was reported by Adekunle et al. [27], who had studied environmental isolates collected from a general hospital in Nigeria. In addition, a prevalence of $17 \%$ (8/47), mainly from door handles, was reported in a study conducted in three government hospitals in Ghana [28].

The prevalence rate obtained in this study was higher than a survey conducted by Mukhiya et al. [29], who obtained 40.7\% (11/27) from environmental isolates collected from hospitals in Nepal, a developing country. The level of healthcare provided by these hospitals had not been specified. The prevalence in our study was also higher than that of Ekrami et al. [30], who obtained an MRSA prevalence of $60.0 \%$ from hospital environmental isolates collected from hospitals in Iran which is also a developing country. South African public hospitals lack funding, have a shortage of resources, are understaffed, and are often overcrowded [31]. These factors greatly affect IPC implementation and may contribute to a lack of hospital hygiene management. The regional hospital (hospital $\mathrm{C}$ ) had the highest number of isolates compared to the other three hospitals. However, patients may act as vectors that translocate hospital-acquired pathogens between hospitals [32]. This was evident in a study conducted by Donker et al. [32], who reported a positive correlation (33.0\%) between patient referrals and the incidence of hospital-acquired pathogens such as MRSA in hospitals in England and the Netherlands. 


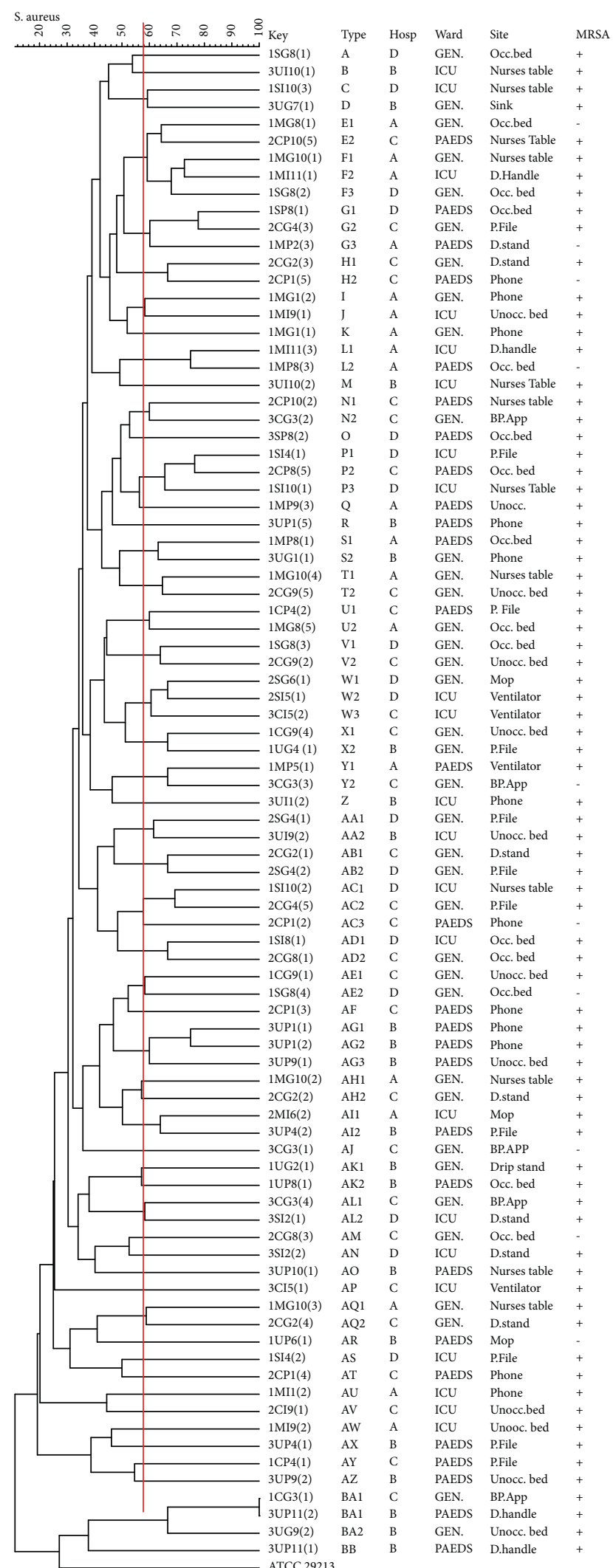

FIGURE 2: ERIC-PCR fingerprinting of MRSA ERIC-type groups of isolates recovered from four public hospitals in KZN, South Africa. An index of $60 \%$, indicated by the solid red line, was used, respectively, to determine similarity and clustering. S. aureus ATCC 29213 was used as the quality control strain.
One of the transmission routes of MRSA is through direct skin contact and shedding of epidermal skin cells [33]. Infected patients or patients that are carriers of MRSA may shed their skin onto the hospital beds. The results also revealed that there was a significant relationship $(p<0.05)$ between the mecA gene and the site (shown in Table S2). These results are similar to those of Adwan et al. [34], who also reported a significant relationship. It is interesting to note that the highest prevalence of MRSA was obtained from the unoccupied beds compared to other sites in the study (Figure 1). These results are an indication that IPC protocols pertaining to the laundry or hospital bed disinfection were unsatisfactory as the presence of MRSA may have emanated from a previously admitted patient. The results showed that the occupied and unoccupied beds accounted for $32.4 \%$ of the total isolates. These results indicate substandard cleaning agents or improper execution of IPC protocols. Contamination of unoccupied beds may occur before the patient has had direct contact with the site. These results are consistent with the results obtained by Pinon et al. [14], who conducted a study in a hospital in France as $S$. aureus has been reported to contaminate bed linen even though the sheets and pillowcases had been washed [14]. A possible reason may be attributed to the survival abilities of $S$. aureus for one to 90 days or more on fabrics and materials such as cotton, cotton terry, cotton-polyester blend, polyester, and polypropylene plastic [35].

$S$. aureus has been associated with a low infectious dosage indicating that $S$. aureus is highly contagious even in small amounts; only 15 cells of $S$. aureus introduced into experimental lesions were enough to result in infection [36]. Therefore, patients through direct contact with the surface may be exposed to the pathogen through open wounds or postsurgical procedures, thus suggesting that contaminated surfaces may be an essential and underappreciated source of MRSA transmission [33]. Transmission of pathogens is dependent on a range of factors which are but not limited to the viability of the pathogen on that environmental site, relative humidity, the frequency of contact between patients, healthcare workers, and contaminated surfaces, ambient temperature, and the dose of the transmitted pathogen [34].

The antibiotic susceptibility testing results showed that only $46 \%$ of the isolates were resistant to cefoxitin, the antibiotic used as an indication for methicillin resistance of S. aureus (MRSA) isolates, according to CLSI recommendations (M100-S27, 2017). The results obtained were contrary when compared to the high mecA gene presence of $89 \%$ indicated by the PCR results. S. aureus strains that are methicillin resistant carry either the mecA, mecB, or mecC genes. These genes are acquired genetic determinants that encode for PBP2a or PBP2a, low-affinity penicillin-binding proteins [26]. PBP2a has a very low affinity for most $\beta$-lactam antibiotics [26].

The level of mecA transcription or presence in isolates does not predict the level of phenotypic methicillin resistance. A possible explanation is found in the work of Lee et al. [37], who identified three attributing factors. The first factor is stringent stress response (the bacteria's reaction to different stress conditions, such as amino acid, fatty acid, 
iron limitation, and heat shock) [37]. The work of Boylevavra et al. [38] presented the second factor. The inactivation of $\mathrm{VraS}$ was shown to have induced the transcription of $m e c A$ but did not increase the level of PBP2a activity [38]. VraS is a part of the regulatory system made up of the sensor protein VraS and response regulator protein VraR. These proteins are involved in controlling the cell wall peptidoglycan biosynthesis [37]. The third factor is the chaperone foldase protein, $\operatorname{Prs} A$, which changes the amount of correctly folded PBP2a that is found in the membrane. As a result, this would in turn affect the methicillin resistance without hindering the transcription of the mecA gene. Thus, these factors are an indication that the gene presence does not determine antibiotic resistance [37].

The presence of the $L u k S / F-P V$ gene is commonly associated with strains of community-acquired MRSA; however, this varies based on geographic locations [39]. The virulence gene for Panton-Valentine leucocidin, $L u k S / F-P V$, was detected in $53.5 \%$ of the isolates. This percentage was higher than that previously reported by Adwan et al. [34], who obtained an incidence of $14.3 \%$ in a similar study. The presence of this gene indicates the possible production of a toxin, which induces the formation of virulence pores in leukocytes [34]. If patients are exposed to these strains, this may result in severe chronic skin infections or necrotising pneumonia with an extremely high mortality rate even in young and healthy patients. The presence of the $L u k S / F-P V$ gene obtained in this study is contrary to the results of Bhatta et al. [39], who reported that there was no presence of this gene among hospital environment isolates collected in Nepal, which may have been an indication of the gene not being associated with isolates from the hospital environment.

There are limited studies that have implemented ERICPCR to evaluate the clonality of $S$. aureus isolates from the hospital environment. The ERIC-PCR results obtained in this study showed a high diversity between the MRSA isolates collected. The results showed that 2 of the isolates were nontypeable with ERIC-PCR. These results were comparable to the study conducted by Adwan et al. [34] whose results indicated that two isolates out of 265 swabs collected from two hospitals in Iran were nontypeable using ERIC-PCR. The ERIC-PCR results indicated that three of the six major ERIC types were shared between the district hospital (D) and regional hospital (C) indicating a potential interclonal spread of MRSA clones as district hospitals fall under level 1 of the referral system of South African hospitals [40]. Patients are referred from the district hospitals to the local and regional hospital whenever the correct health service cannot be offered. These results further highlight the transmission risk of pathogens between hospitals due to referrals. The spread of MRSA was also observed between two sites of the same hospital ward (Figure 2) suggesting an intraclonal spread of MRSA. The failure to adhere to IPC measures is a likely cause. However, the study was limited by the lack of information on the infection control practices at these hospitals that precluded the comparative analyses of the IPC practices between different hospital settings, warranting further studies to ascertain this.

\section{Conclusion}

In summary, the study highlights the prevalence and phenotypic and genotypic characterizations of $S$. aureus indicating that the hospital environments could act as potential reservoirs in the transmission of MRSA encoding diverse antibiotic resistance and virulence genes in South African public hospitals. This was further supported by ERIC-PCR typing showed by the recovery of genetically similar MRSA isolates from different surfaces within the same hospital (intraclonal spread) and between different hospitals (interclonal spread), which can be further disseminated to other sites if IPC measures are suboptimal. We conceive that our work can be used as a framework for future surveillance initiatives to improve hospital hygiene through IPC-centred strategies to minimize the presence of drug-resistant and pathogenic microorganisms that are present in the hospital environment. This would reduce hospital-acquired infections, due to contaminated sites, and provide a safe environment for patients and healthcare workers.

\section{Data Availability}

The generated data used to support the findings of this study are included within the article.

\section{Ethical Approval}

This study was approved by the Biomedical Research and Ethics Committee (BREC) of the University of KwaZuluNatal (reference no. BE606/16) and listed on the Health Research and Knowledge Management Database (HRKM 098/17) of the Department of Health (reference no. KZ 2017RP24 630). In addition, the district health department and hospital management provided gatekeepers' approval.

\section{Disclosure}

Any views, findings, conclusions, or recommendations conveyed in this study are those of the authors; thus, they do not represent the organisations that supported the study.

\section{Conflicts of Interest}

The authors declare that they have no conflicts of interest.

\section{Authors' Contributions}

All co-conceptualized the study. SM collected the samples, performed the laboratory work, and wrote the article. SM, LB, and DGA analyzed the data. SM, COS, DGA, and LB contributed to the vetting of the results. SM, COS, DGA, LB, and $\mathrm{OZ}$ critically revised the manuscript.

\section{Acknowledgments}

The authors would like to acknowledge the participating hospitals for allowing the present study. They would also like to thank Prof. Olaniran Ademola for access to BioNumerics 
software. College of Health Sciences Young Researchers Grant Competition (LA Bester) of the University of KwaZulu-Natal funded this study.

\section{Supplementary Materials}

Table S1: description of the samples collected from hospitals, wards, and sampling sites. Table S2: Fischer's exact test and Pearson's chi-square test for virulence and resistance genes from eleven frequently touched sites, wards, and hospitals. Table S3: comparison of Pearson's correlation for virulence and resistance genes detected in $S$. aureus environmental isolates from four public sector hospitals. (Supplementary Materials)

\section{References}

[1] A. Revelas, "Healthcare-associated infections: a public health problem," Nigerian Medical Journal, vol. 53, no. 2, pp. 59-64, 2012.

[2] J. Liu, D. Chen, B. M. Peters et al., "Staphylococcal chromosomal cassettes mec (SCCmec): a mobile genetic element in methicillin-resistant Staphylococcus aureus," Microbial Pathogenesis, vol. 101, pp. 56-67, 2016.

[3] G. De Angelis, A. Murthy, J. Beyersmann, and S. Harbarth, "Estimating the impact of healthcare-associated infections on length of stay and costs," Clinical Microbiology and Infections, vol. 16, no. 12, pp. 1729-1735, 2010.

[4] M. Rahmqvist, A. Samuelsson, S. Bastami, and H. Rutberg, "Direct health care costs and length of hospital stay related to health care-acquired infections in adult patients based on point prevalence measurements," American Journal of Infection Control, vol. 44, no. 5, pp. 500-506, 2016.

[5] V. D. Rosenthal, W. R. Jarvis, S. Jamulitrat et al., "Socioeconomic impact on device-associated infections in pediatric intensive care units of 16 limited-resource countries," Pediatric Critical Care Medicine, vol. 13, no. 4, pp. 399-406, 2012.

[6] World Health Organization, Global Antimicrobial Resistance Surveillance System (GLASS) Report: Early Implementation 2017-2018, World Health Organization, Geneva, Switzerland, 2018.

[7] M. Otto, "Staphylococcus aureus toxins," Current Opinion in Microbiology, vol. 17, pp. 32-37, 2014.

[8] N. Malachowa and F. R. DeLeo, "Mobile genetic elements of Staphylococcus aureus," Cellular and Molecular Life Sciences, vol. 67, no. 18, pp. 3057-3071, 2010.

[9] S. Y. C. Tong, J. S. Davis, E. Eichenberger, T. L. Holland, and V. G. Fowler, "Staphylococcus aureus infections: epidemiology, pathophysiology, clinical manifestations, and management," Clinical Microbiology Reviews, vol. 28, no. 3, pp. 603-661, 2015.

[10] J. M. Blair, M. A. Webber, A. J. Baylay, D. O. Ogbolu, and L. J. V Piddock, Molecular Mechanisms of Antibiotic Resistance, Nature Publishing Group, vol. 13Berlin, Germany, , 2014.

[11] C. Milheiriço, H. de Lencastre, and A. Tomasz, "MRSA strains carrying the novel mecC gene: full genome sequencing identifies in the genetic background several determinants that modulate the resistant phenotype," Antimicrobial Agents and Chemotherapy, vol. 61, Article ID ACC-02500, 2017.

[12] J. A. Otter, S. Yezli, J. A. G. Salkeld, and G. L. French, "Evidence that contaminated surfaces contribute to the transmission of hospital pathogens and an overview of strategies to address contaminated surfaces in hospital settings," American Journal of Infection Control, vol. 41, no. 5, pp. S6-S11, 2013.

[13] D. Mulvey, P. Redding, C. Robertson et al., "Finding a benchmark for monitoring hospital cleanliness," Journal of Hospital Infection, vol. 77, no. 1, pp. 25-30, 2011.

[14] A. Pinon, J. Gachet, V. Alexandre, S. Decherf, and M. Vialette, "Microbiological contamination of bed linen and staff uniforms in a hospital," Advances in Microbiology, vol. 2013, 2013.

[15] E. O. Nwankwo, N. Ekwunife, and K. C. Mofolorunsho, "Nosocomial pathogens associated with the mobile phones of healthcare workers in a hospital in Anyigba, Kogi state, Nigeria," Journal of Epidemiology and Global Health, vol. 4, no. 2, pp. 135-140, 2014.

[16] E. Creamer, A. C. Shore, E. C. Deasy et al., "Air and surface contamination patterns of meticillin-resistant Staphylococcus aureus on eight acute hospital wards," Journal of Hospital Infection, vol. 86, no. 3, pp. 201-208, 2014.

[17] Department of Health, "National health act 2003: national health insurance policy," South African Government Notices, 2017, https://www.gov.za/sites/default/files/gcis_document/ 201707/40955gon627.pdf.

[18] B. C. Millar, X. Jiru, J. E. Moore, and J. A. P. Earle, “A simple and sensitive method to extract bacterial, yeast and fungal DNA from blood culture material," Journal of Microbiological Methods, vol. 42, no. 2, pp. 139-147, 2000.

[19] O. G. Brakstad, K. Aasbakk, and J. A. Maeland, "Detection of Staphylococcus aureus by polymerase chain reaction amplification of the nuc gene," Journal of Clinical Microbiology, vol. 30, no. 7, pp. 1654-1660, 1992.

[20] S. M. Hoseini Alfatemi, M. Motamedifar, N. Hadi, and H. Sedigh Ebrahim Saraie, "Analysis of virulence genes among methicillin resistant Staphylococcus aureus (MRSA) strains," Jundishapur Journal of Microbiology, vol. 7, no. 6, Article ID e10741, 2014.

[21] L. Kuntová, R. Pantůček, J. Rájová et al., "Characteristics and distribution of plasmids in a clonally diverse set of methicillinresistant Staphylococcus aureus strains," Archives of Microbiology, vol. 194, no. 7, pp. 607-614, 2012.

[22] K. Thong, Y. Hanifah, K. Lim, and M. Yusof, "ermA, ermC, tet $\mathrm{M}$ and tetK are essential for erythromycin and tetracycline resistance among methicillin-resistant Staphylococcus aureus strains isolated from a tertiary hospital in Malaysia," Indian Journal of Medical Microbiology, vol. 30, no. 2, p. 203, 2012.

[23] Clinical and Laboratory Standards Institute, Performance Standards for Antimicrobial Susceptibility Testing, CLSI Supplement M100, Wayne, PA, USA, 27th edition, 2017.

[24] A.-P. Magiorakos, A. Srinivasan, R. B. Carey et al., "Multidrug-resistant, extensively drug-resistant and pandrug-resistant bacteria: an international expert proposal for interim standard definitions for acquired resistance," Clinical Microbiology and Infections, vol. 18, no. 3, pp. 268-281, 2012.

[25] B. G. Mitchell, W. Digney, P. Locket, and S. J. Dancer, "Controlling methicillin-resistantStaphylococcus aureus(MRSA) in a hospital and the role of hydrogen peroxide decontamination: an interrupted time series analysis," BMJ Open, vol. 4, no. 4, Article ID e004522, 2014.

[26] M. Otto, "MRSA virulence and spread," Cellular Microbiology, vol. 14, no. 10, pp. 1513-1521, 2012.

[27] O. C. Adekunle, T. O. Oyakeye, and Y. O. Adesiji, "Molecular detection of methicillin resistance genes from clinical sources and hospital environments," Microbiology Research Journal International, vol. 28, no. 5, pp. 1-7, 2019. 
[28] C. K. S. Saba, J. K. Amenyona, and S. W. Kpordze, "Prevalence and pattern of antibiotic resistance of Staphylococcus aureus isolated from door handles and other points of contact in public hospitals in Ghana," Antimicrobial Resistance and Infection Control, vol. 6, no. 1, p. 44, 2017.

[29] R. K. Mukhiya, A. Shrestha, S. K. Rai et al., "Prevalence of methicillin-resistant Staphylococcus aureus in hospitals of Kathmandu valley," Nepal Journal of Science and Technology, vol. 13, no. 2, pp. 185-190, 2012.

[30] A. Ekrami, A. Kayedani, M. Jahangir, E. Kalantar, and M. Jalali, "Isolation of common aerobic bacterial pathogens from the environment of seven hospitals, Ahvaz, Iran," Archive of SID, vol. 4, pp. 75-82, 2011.

[31] S. Ranchod, C. Adams, R. Burger et al., "South Africa's hospital sector: old divisions and new developments," South African Health Review, vol. 2017, pp. 101-110, 2017.

[32] T. Donker, J. Wallinga, R. Slack, and H. Grundmann, "Hospital networks and the dispersal of hospital-acquired pathogens by patient transfer," PLoS One, vol. 7, no. 4, Article ID e35002, 2012.

[33] U. Stiefel, J. L. Cadnum, B. C. Eckstein, D. M. Guerrero, M. A. Tima, and C. J. Donskey, "Contamination of hands with methicillin-resistant Staphylococcus aureus after contact with environmental surfaces and after contact with the skin of colonized patients," Infection Control \& Hospital Epidemiology, vol. 32, no. 2, pp. 185-187, 2011.

[34] G. Adwan, H. Shaheen, K. Adwan, and A. Barakat, "Molecular characterization of methicillin resistant Staphylococcus aureus isolated from hospitals environments and patients in Northern Palestine," Epidemiology, Biostatistics and Public Health, vol. 12, no. 3, 2015.

[35] A. N. Neely and M. P. Maley, "Survival of enterococci and staphylococci on hospital fabrics and plastic," Journal of Clinical Microbiology, vol. 38, no. 2, pp. 724-726, 2000.

[36] J. A. Otter, S. Yezli, and G. L. French, "The role of contaminated surfaces in the transmission of nosocomial pathogens," in Use of Biocidal Surfaces for Reduction of Healthcare Acquired Infections, pp. 27-58, Springer International Publishing, London, UK, 2014.

[37] A. S. Lee, H. De Lencastre, J. Garau et al., Methicillin-Resistant Staphylococcus aureus, Nature Publishing Group, vol. 4, pp. 1-23, , Berlin, Germany, 2018.

[38] S. Boyle-vavra, S. Yin, and R. S. Daum, "The VraS/VraR twocomponent regulatory system required for oxacillin resistance in community-acquired methicillin-resistantStaphylococcus aureus," FEMS Microbiology Letters, vol. 262, no. 2, pp. 163-171, 2006.

[39] D. R. Bhatta, L. M. Cavaco, G. Nath et al., "Association of Panton Valentine Leukocidin (PVL) genes with methicillin resistant Staphylococcus aureus (MRSA) in Western Nepal: a matter of concern for community infections (a hospital based prospective study)," BMC Infectious Diseases, vol. 1-6, p. 1, 2016.

[40] KwaZulu-Natal Department of Health, Referral System: Levels of Healthcare, KwaZulu-Natal Department of Health, Pietermaritzburg, South Africa, 2020, http://www.kznhealth.gov. za/Referral-system.htm. 